\title{
Type II cyclic guanosine monophosphate-dependent protein kinase inhibits Rac1 activation in gastric cancer cells
}

\author{
YING WANG, YONGCHANG CHEN, MIN WU, TING LAN, YAN WU, YUEYING LI and HAI QIAN \\ Department of Physiology, School of Medicine, Jiangsu University, Zhenjiang, Jiangsu 212013, P.R. China
}

Received June 17, 2014; Accepted March 27, 2015

DOI: $10.3892 / \mathrm{ol} .2015 .3173$

\begin{abstract}
Enhanced motility of cancer cells is a critical step in promoting tumor metastasis, which remains the major cause of gastric cancer-associated mortality. The small GTPase Racl is a key signaling component in the regulation of cell migration. Previous studies have demonstrated that Rac1 activity may be regulated by protein kinase $\mathrm{G}$ (PKG); however, the underlying mechanism is not yet clear. The current study aimed to investigate the effect of type II cyclic guanosine monophosphate (cGMP)-dependent protein kinase (PKG II) on Rac1 activity. The human gastric cancer cell line AGS was infected with adenoviral constructs encoding PKG II to increase the expression of this enzyme, and treated with a cGMP analog (8-pCPT-cGMP) to induce its activation. A Transwell assay was employed to measure cell migration, and the activity of Racl was assessed using a pull-down assay. Immunoprecipitation was used to isolate the Rac1 protein. Phosphorylation of phosphatidylinositol 4,5 bisphosphate 3 kinase (PI3K) and its downstream effecter protein kinase B (Akt) are associated with lysophosphatidic acid (LPA)-induced motility/migration of cancer cells. Extracellular signal regulated kinase (ERK) is the major signaling molecule of the Mitogen activated protein kinase (MAPK) mediated signaling pathway. ERK and its upstream activator MAPK kinase (MEK) are also involved in LPA-induced motility/migration of cancer cells. Phosphorylation of PI3K/Akt, MEK/ERK and enriched Rac1 were detected by western blotting. The results revealed that blocking the activation of Rac1 by ectopically expressing an inactive Rac1 mutant (T17N) impeded LPA-induced cell migration. Increased PKG II activity inhibited LPA-induced migration and LPA-induced activation of Rac1; however, it had no effect on the phosphorylation of Rac1. PKG II also inhibited the activation of PI3K/Akt and MEK/ERK mediated signaling, which is important for LPA-induced Racl activation. These
\end{abstract}

Correspondence to: Professor Yongchang Chen, Department of Physiology, School of Medicine, Jiangsu University, 301 Xuefu Road, Zhenjiang, Jiangsu 212013, P.R. China

E-mail: ycchen54@ujs.edu.cn

Key words: type II cGMP-dependent protein kinase, inhibition, Rac1, gastric cancer cells results suggest that PKG II affects LPA-stimulated migration of AGS cells by blocking Rac1 activation, via inhibition of PI3K/Akt and MEK/ERK mediated signaling.

\section{Introduction}

Gastric cancer accounts for a considerable amount of global cancer mortality. It is most frequently detected in its advanced stages. Peritoneal metastases in advanced gastric cancer remain the leading reason for noncurative resection, recurrence following surgery and poor outcomes (1). Type II cyclic guanosine monophosphate (cGMP)-dependent protein kinase (PKG II), a serine/threonine kinase, is an important regulator of diverse cellular processes. Although classically recognized for its ability to modulate intestinal secretion, bone growth and nervous system functions (2-4), PKG II has also been reported to act as an inhibitory component of signal transduction processes in certain cancer cell types. Swartling et al (5) found that this kinase was involved in regulating cell proliferation in glioma cells. Fallahian et al (6) evaluated the significance of the downregulation of PKG II expression in breast cancer and found that PKGII expression was downregulated in the breast tumors compared to those of normal tissue counterparts, which is an important evidence to support the antitumor activity of this kinase. Previous results from our laboratory demonstrated that PKG II inhibited the proliferation and migration of gastric cancer cell lines through the suppression of epidermal growth factor (EGF)-induced activation of the EGF receptor and related signal transduction pathways $(7,8)$.

Rho guanosine triphosphatases (GTPases) are members of the small GTP-binding protein family that are involved in diverse cell functions, including cytoskeletal organization, migration, transformation, differentiation and proliferation (8). Several members of this family have been shown to be important in regulating cell migration: RhoA, which stimulates the formation of actin stress fibers; Rac1, which promotes the process of membrane ruffling; and Cdc42, which enhances the extension of filopodia (9). Rho GTPases work as sensitive molecular switches, existing in an inactive guanosine diphosphate (GDP)-bound form or an active GTP-bound form. Activation of Rho GTPases is regulated by guanine nucleotide dissociation inhibitors (GDIs), guanine nucleotide exchange factors, and GTPase activating proteins (10). Phosphorylation of Rho GTPases is an additional mechanism by which the 
activity of these proteins may be modulated, usually leading to their functional inactivation $(11,12)$. Our previous results indicated that PKG II inhibits lysophosphatidic acid (LPA)-induced cell migration, by phosphorylation of RhoA at Ser188, thereby decreasing its activation (13).

The present study aimed to examine the potential inhibitory effect of PKG II on Rac1 activity in LPA-induced cell migration, and the underlying mechanism by which PKG II inhibits Rac1 activation. Accumulating evidence indicates that phosphorylation may be an important mechanism for the regulation of Rac1 activation $(12,14)$. Phosphorylation of Rac1 at Ser71 has been reported to modulate downstream signaling by inhibiting the interaction of Rac1 with its effectors (12). In addition, phosphatidylinositol-4,5-bisphosphate 3-kinase/protein kinase B (PI3K/Akt), mitogen-activated protein kinase kinase/extracellular signal-regulated kinase $(\mathrm{MEK} / \mathrm{ERK})$ and phospholipase C $\gamma 1$ (PLC $\gamma 1)$-mediated signal transduction have been implicated in the Rac1 signaling pathway in various human cancer cell lines (15-18). Therefore, the current study also aimed to establish the effects of inhibiting these pathways on Racl activation, and the ability of PKG II to directly phosphorylate Rac1.

\section{Materials and methods}

Cell lines, plasmids and reagents. The human gastric cancer cell line AGS and human embryonic kidney 293A cells were provided by the Institute of Cell Biology (Shanghai, China). Adenoviral vectors encoding $\beta$-galactosidase (pAd-LacZ) and PKG II (pAd-PKG II) were provided by Dr. Gerry Boss and Dr. Renate Pilz of the University of California (San Diego, CA, USA). The pEGFP-C2 vector containing dominant negative Rac1 T17N insert was provided by Dr. Gu Luo of Nanjing Medical University. Dulbecco's modified Eagle's medium (DMEM) and fetal bovine serum (FBS) were purchased from Gibco (Grand Island, NY, USA). The polyclonal rabbit anti-human PKG II was from Abgent Biotechnology (San Diego, CA, USA, cat no. AP8001a) and the application dilution was 1:200. The polyclonal rabbit anti-human Racl was from Signalway Antibody LLC (College Park, MD, USA, cat no. 21201) and the application dilution was 1:500. The polyclonal rabbit anti human p-Rac1/Cdc42 (Ser71) and rabbit anti-human p-MEK (Ser217/221) antibodies were from Cell Signaling Technology (Danvers, MA, USA, cat no. 2461 and cat no. $9121 \mathrm{~S}$ respectively) and the application dilutions were all 1:1,000. The polyclonal rabbit anti-human p-Ser/Thr antibody was from Abcam (Cambridge, MA, USA, cat no. ab17464) and the application dilution was 1:1,000. The polyclonal rabbit anti-human GFP antibody (cat no. BS6507), polyclonal rabbit anti-human p-ERK (Thr202/Tyr204) antibody (cat no. BS5016), polyclonal rabbit anti-human anti-p Akt (Ser473) antibody (cat no. BS4006), and polyclonal rabbit anti-human p-PI3K P85 (Tyr458)/P55 (Tyr199) antibody (cat no. BS4605) were purchased from Bioworld Technology (St. Louis Park, MN, USA) and the application dilutions were all 1:500. Horseradish peroxidase (HRP) conjugated polyclonal goat anti-mouse IgG and polyclonal goat anti-rabbit IgG secondary antibodies (cat no. 115-035-003 and 111-035-003, respectively) were from Jackson Immuno Research Laboratories (West Grove, PA, USA) and the application dilutions were all 1:10,000. The monoclonal mouse anti-Tag protein FLAG antibody was used at a dilution of 1:2,000, LPA, U73122 and U0126 were from Sigma-Aldrich (St. Louis, MO, USA, cat no. F1804, cat no. L7260, cat no. U6756 and cat no. U120 respectively). The cell permeable cGMP analog 8-pCPT-cGMP was from Calbiochem (San Diego, CA, USA). Mouse anti-FLAG, LPA, U73122 and U0126 were from Sigma-Aldrich (St. Louis, MO, USA). LY294002 was from Beyotime (Jiangsu, China). The cell transfection reagent Lipofectamin 2000, PureLink RNA Mini kit and SuperScript III were from Invitrogen Life Technologies (Carlsbad, CA, USA). Electrochemiluminescence (ECL) reagents were from Millipore (Billerica, MA, USA). All other reagents used were of analytical grade.

Preparation of adenoviral vectors. 293A cells were transfected with pAd-LacZ or pAd-PKG II, and cultured in DMEM, supplied with $10 \% \mathrm{FBS}$ and maintained at $37^{\circ} \mathrm{C}$ in a humidified incubator with $95 \%$ air and $5 \% \mathrm{CO}_{2}$ for up to 10 days until cytopathic effects were seen. The cells and culture medium were subsequently harvested by pipetting up and down gently in the growth medium until the cells were completely resuspended. The cell suspension was transferred to a screw cap centrifuge tube and the cells were pelletted by low speed centrifugation (19) and then underwent three freezing-thawing cycles. Ad-LacZ and Ad-PKG II were amplified by using the supernatant containing these adenoviruses to infect new 293A cells. The amplified adenoviral preparations were titrated to determine the number of plaque forming units per $\mathrm{ml}$, and stored at $-80^{\circ} \mathrm{C}$ until use.

Cell culture, transfection and infection. AGS cells were cultured in DMEM supplemented with $10 \% \mathrm{FBS}$, and maintained at $37^{\circ} \mathrm{C}$ in a humidified atmosphere of $95 \%$ air and $5 \% \mathrm{CO}_{2}$. The medium was replaced every 2 days and the cells were sub-cultured at confluence. For transfection with plasmids, cells were sub-cultured the previous day, and transfection was conducted according to the manufacturer's instructions. The pEGFP-C2 was used as a control and the pRac1-T17N and pFlag-Rac1 were used to express the dominant negative mutant Rac1 and Flag-tagged Rac1, respectively. At 1 day prior to infection with Ad-LacZ and Ad-PKG II, cells were freshly seeded at $70-80 \%$ confluence.

Cloning constructs. To generate FLAG-tagged wild type Rac1, total RNA from AGS cells was isolated using a PureLink RNA Mini kit, according to the manufacturer's instructions. The initial cDNA strand was synthesized using SuperScript III, according to the manufacturer's instructions. A fragment encoding the full-length Rac1, with a HindIII site at the $\mathrm{N}$ terminus and a Bam HI site at the $\mathrm{C}$ terminus, was amplified by DNA by polymerase chain reaction (PCR). The $5^{\prime}$ primer for wild type Rac1 was 5'-CCC AAG CTT ATG CAG GCC ATC AAG TGT GTG-3', and the 3' primer was 5'-CGC GGA TCC CAA CAG CAG GCA TTT TCT CTT CC-3'. The PCR was performed with $50 \mathrm{ng}$ of genomic DNA, $0.2 \mu \mathrm{M}$ of each primer, and 1X PrimeSTAR Max DNA polymerase (cat no. DR045A, Takara, Dalian, China). The PCR amplification was performed as follows: initial denaturation at $94^{\circ} \mathrm{C}$ for $2 \mathrm{~min}$, followed by 30 cycles of denaturation at $94^{\circ} \mathrm{C}$ for $15 \mathrm{sec}$, annealing at $64^{\circ} \mathrm{C}$ 
for $5 \mathrm{sec}$ and elongation at $72^{\circ} \mathrm{C}$ for $30 \mathrm{sec}$ and then a final elongation at $72^{\circ} \mathrm{C}$ for $1 \mathrm{~min}$. The PCR products were cleaved using HindIII-BamHI, and the target fragment was cloned into the expression vector p3XFlag-myc-CMV-24.

Transwell migration assay. The migration activity of AGS cells was detected using a transwell system (BD BioCoat Control, $8.0 \mathrm{~mm}$ PET membrane, 24-well cell culture inserts; BD Biosciences, San Jose, CA, USA). Following trypsinization, $5 \times 10^{4}$ cells were seeded into the upper chamber in serum-free culture medium. For LPA treatment, LPA $(10 \mu \mathrm{M})$ was added to the culture medium. For cGMP treatment, cells were incubated with 8-pCPT-cGMP $(250 \mu \mathrm{M})$ for $1 \mathrm{~h}$ prior to the addition of LPA. Migration of the cells to the bottom of the membrane was induced by incubation with medium containing $10 \%$ FBS in the lower chamber for $12 \mathrm{~h}$ at $37^{\circ} \mathrm{C}$ in a tissue culture incubator. The cells remaining in the upper chamber were removed with cotton swabs. Cells that had migrated to the lower side of the membrane were fixed in $4 \%$ paraformaldehyde solution for $30 \mathrm{~min}$, stained by Giemsa solution (10 min incubation) and rinsed with water. Stained cells were subsequently examined by light microscopy. Migrated cells were counted in five randomly selected fields per insert, and mean values were calculated. All experiments were performed in triplicate for each migration condition.

Western blot analysis. Protein samples were subjected to SDS-PAGE (8-12\%) according to the molecular size of the target protein; electrophoresis and membrane transfer was performed following the manufacturer's protocol (Bio-Rad, Hercules, CA, USA). The membranes were incubated with primary antibodies overnight at $4{ }^{\circ} \mathrm{C}$ in tris-buffered saline and Tween 20 (TBS-T; 0.1\% Tween 20), and the corresponding secondary antibodies were incubated for $1 \mathrm{~h}$ at RT in TBS-T (0.1\% Tween-20), with three washes following each incubation. ECL reagents were used to detect positive bands on the membrane. For densitometry analysis, digital images of the positive bands were obtained with Chemidoc XRS and analyzed using Quantity One (Bio-Rad). Results were presented as the ratio of target protein : loading control.

In vitro pull-down assay. $48 \mathrm{~h}$ after transfection or infection, cells at $\sim 90 \%$ confluence on $100 \mathrm{~mm}$ culture plates were washed three times with cold PBS and harvested in lysis buffer (25 mM HEPES pH 7.5, $150 \mathrm{mM} \mathrm{NaCl}, 1 \% \mathrm{NP} 40$, $10 \%$ glycerol, $25 \mathrm{mM} \mathrm{NaF}, 10 \mathrm{mM} \mathrm{MgCl} 2,0.25 \%$ sodium deoxycholate, $1 \mathrm{mM}$ EDTA, $1 \mathrm{mM} \mathrm{Na} \mathrm{VO}_{4}, 10 \mathrm{mg} / \mathrm{ml}$ aprotinin, and $10 \mathrm{mg} / \mathrm{ml}$ leupeptin). For LPA treatment, $1 \mu \mathrm{M}$ LPA was added to the culture medium for $1 \mathrm{~min}$ prior to cell lysis. For cGMP treatment, cells were incubated with 8-pCPT-cGMP $(250 \mu \mathrm{M})$ for $1 \mathrm{~h}$ prior to LPA treatment. The supernatant obtained by centrifugation $(13,800 \mathrm{xg}, 10 \mathrm{~min})$ was subsequently incubated with GST-Pak1 protein binding domain (GST-PBD; provided by Dr. Keith Burridge in University of North Carolina, Chapel Hill, NC, USA) for $1 \mathrm{~h}$ at $4^{\circ} \mathrm{C}$ with agitation. Following thorough rinsing with lysis buffer, the bound proteins were solubilized in 2X SDS sample buffer and analyzed by western blotting with an anti-Racl antibody. To indicate the amount of protein used in each pull-down assay, $5 \%$ of the input lysate was loaded in the input lane. Densitometry analysis was performed to quantify
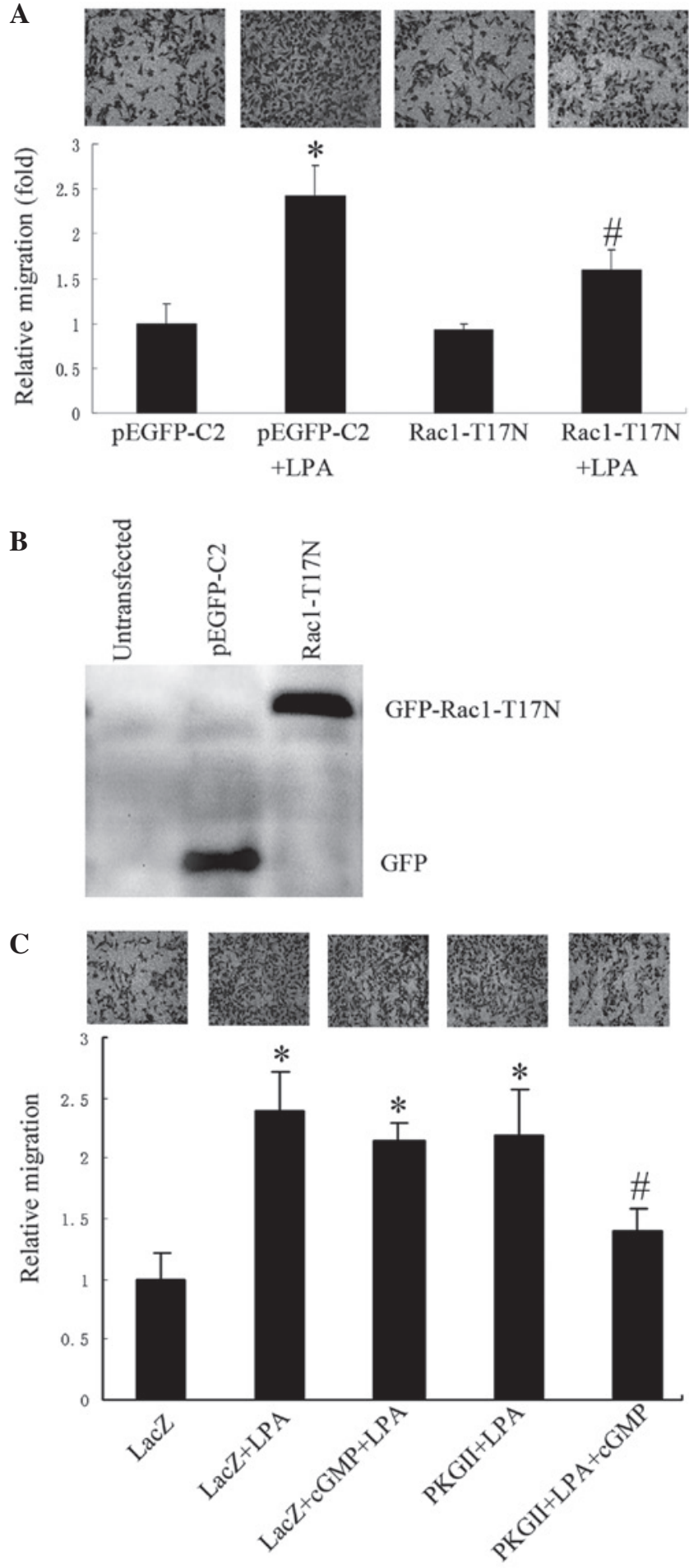

Figure 1. PKG II inhibits LPA-induced cell migration, which is dependent on Rac1 activation. The migration activity of AGS cells was analyzed using transwell assays and cells were examined under a light microscope (images above each graph; magnification, x200). (A) Relative migration of AGS cells transfected with the empty pEGFP-C2 vector, or the vector containing Rac1 T17N, in the presence or absence of LPA (mean \pm SD from three independent experiments performed in duplicate; ${ }^{*} \mathrm{P}<0.01$, compared with pEGFP-C2 group; ${ }^{\#} \mathrm{P}<0.05$, compared with pEGFP-C2+LPA group). (B) Western blot analysis showing expression of the inactive mutant Rac1-T17N in transfected AGS cells, detected by anti-GFP antibody. (C) Relative migration of AGS cells infected with either Ad-LacZ or Ad-PKG II, and treated with LPA or LPA+8-pCPT-cGMP (mean + SD from three independent experiments performed in duplicate; ${ }^{*} \mathrm{P}<0.01$, compared with LacZ group; ${ }^{*} \mathrm{P}<0.05$, compared with LacZ+LPA group, LacZ+cGMP+LPA group and PKG II+LPA group). LPA, lysophosphatidic acid; GFP, green fluorescent protein; cGMP, cyclic guanosine monophospate; PKG II, type II cGMP-dependent protein kinase; $\mathrm{SD}$, standard deviation. 


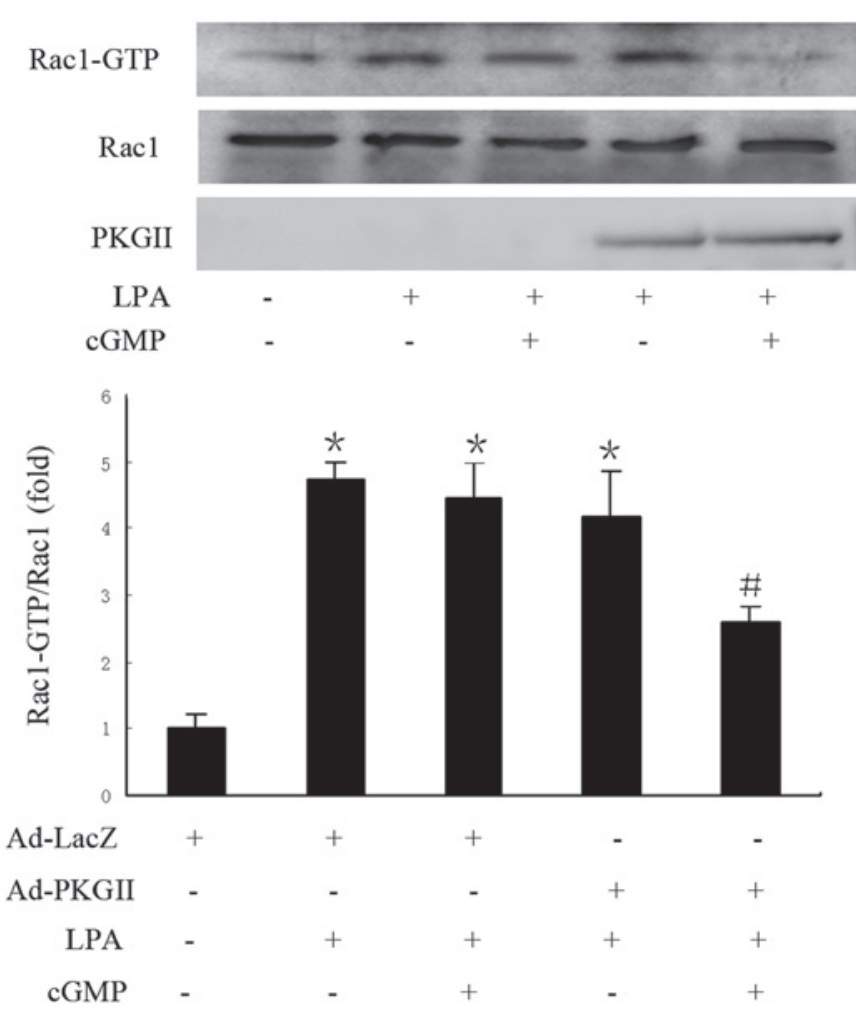

Figure 2. PKG II inhibits LPA-induced Rac1 activation. The graph shows the volume ratio of active (GTP-bound) Rac1 to total Racl in the lysate of cells infected with Ad-LacZ or Ad-PKG II, and treated with LPA or LPA+cGMP (mean \pm standard deviation from three independent experiments; ${ }^{*} \mathrm{P}<0.01$, compared with LacZ group; ${ }^{\text {P }}<0.05$, compared with LacZ+LPA group, LacZ+cGMP+LPA group and PKG II+LPA group). GTP, guanosine triphosphate; PKG II type II cGMP-dependent protein kinase; LPA, lysophosphatidic acid; cGMP, cyclic guanosine monophosphate.

the positive bands, and the raw volume ratio of active Rac1 to total Rac1 was calculated.

Immunoprecipitation. AGS cells grown on $100 \mathrm{~mm}$ culture plate were transfected with FLAG-tagged plasmids containing wild type Rac1. At $6 \mathrm{~h}$ after transfection, the cells were infected by Ad-LacZ or Ad-PKG II. Following a $48 \mathrm{~h}$ incubation, cells were treated with 8-pCPT-cGMP $(250 \mu \mathrm{M})$ for $1 \mathrm{~h}$ before washing twice with cold PBS and lysing with RIPA buffer $(50 \mathrm{mM}$ Tris- $\mathrm{HCl} \mathrm{pH}$ 7.4, $1 \%$ Triton X-100, $1 \mathrm{mM}$ EDTA, $1 \mathrm{mM}$ leupeptin, $1 \mathrm{mM}$ phenylmethylsulfonyl fluoride, $\left.10 \mathrm{mM} \mathrm{NaF}, 1 \mathrm{mM} \mathrm{Na} \mathrm{VO}_{4}\right) 48 \mathrm{~h}$ following the transfection and/or infection process. The supernatant was obtained by centrifugation $(13,800 \mathrm{x} \mathrm{g}, 10 \mathrm{~min})$ and incubated with target antibodies for $12 \mathrm{~h}$ at $4^{\circ} \mathrm{C}$ with agitation. Fresh protein $\mathrm{G}$ conjugated to agarose was subsequently added, followed by a further 2 to $3 \mathrm{~h}$ incubation at $4^{\circ} \mathrm{C}$ with agitation. Immunoprecipitates were centrifuged at $400 \mathrm{xg}$ for $1 \mathrm{~min}$ at $4^{\circ} \mathrm{C}$. The supernatant was discarded and the pellet, which consisted of protein $\mathrm{G}$ conjugated to agarose and Flag-tagged Rac1 protein, was washed four times with binding buffer, prior to resuspension in an equal volume of 2 XSDS sample buffer. The precipitates were subsequently probed with antibodies against the target proteins.

Statistical analysis. The data are presented as the mean \pm standard deviation (SD). Significance was assessed using analysis

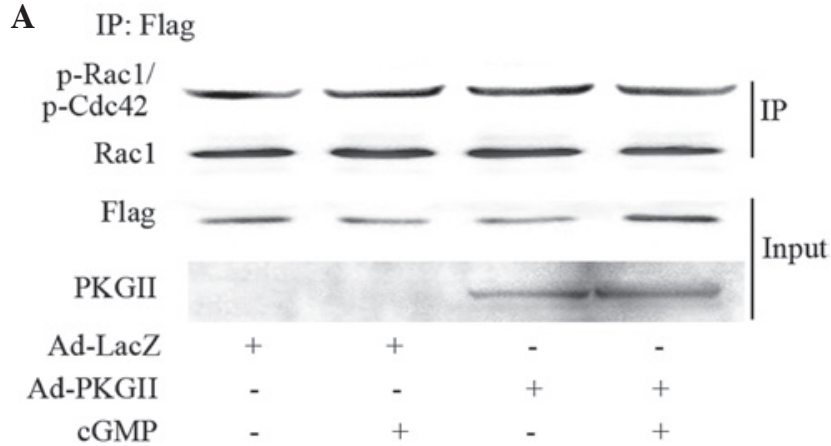

B IP: Flag

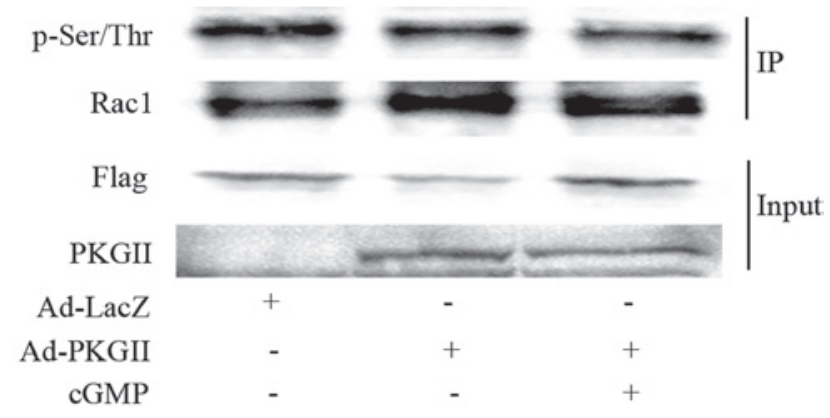

Figure 3. Rac1 is not directly phosphorylated by PKG II. (A) The phosphorylation of Rac1 at Ser71 was analyzed by western blotting with antibody against phospho-Rac1/Cdc42 (Ser71). (B) The phosphorylation of precipitated Rac1 was analyzed by western blotting with antibody against pan phospho-Ser/Thr. Results shown are representative of three independent experiments. IP, immunoprecipitation; PKG II, type II cGMP-dependent protein kinase; cGMP, cyclic guanosine monophosphate; Ser, serine; Thr, threonine.

of variance with SPSS statistical software. $\mathrm{P}<0.05$ was considered to indicate a statistically significant difference.

\section{Results}

PKG II inhibits LPA-induced cell migration, which requires Racl activation. To evaluate the role of Racl in LPA-induced migration of gastric cancer cells, Racl activity in AGS cells was reduced by transfection with a plasmid (pEGFP-C2) containing cDNA of Rac1 T17N (a dominant negative mutant of Rac1), and cell migration following LPA stimulation ( $10 \mu \mathrm{M}$ for $12 \mathrm{~h}$ ) was assessed. Cells transfected with the empty vector exhibited significantly increased migration activity following the addition of LPA compared with controls. However, in cells transfected with the Rac1 T17N expression vector, the stimulatory effect of LPA on cell migration was significantly lower compared with those transfected with the empty vector (Fig. 1A). Expression levels of Rac1-T17N were verified using western blotting with anti-GFP antibody (Fig. 1B). The results indicated that the activation of Racl was essential for LPA-stimulated migration of gastric cancer cells.

Subsequently, the effects of PKG II on LPA-induced migration were investigated. AGS cells infected with Ad-LacZ or Ad-PKG II were treated with 8-pCPT-cGMP (a cGMP analog for the activation of PKG II) and/or LPA. A transwell migration assay revealed that treatment with 8-pCPT-cGMP significantly inhibited LPA-induced migration in the cells infected with 


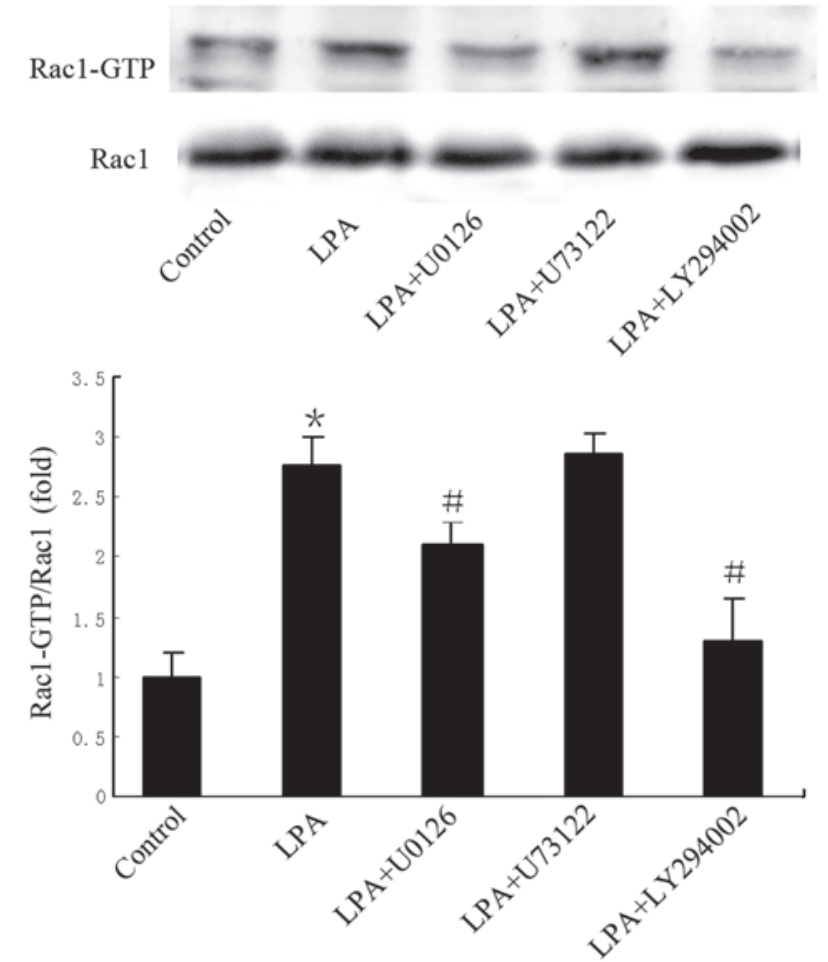

Figure 4. U1026/LY294002 inhibits LPA-induced activation of Rac1. Top panel: Western blot analysis result. Racl-GTP represents the level of active Rac1 with different treatments. Rac1 represents the level of total Rac1 in the cell lysate. Bottom panel: The graph shows the volume ratio of active (GTP-bound) Rac1 to total Rac1 in the lysate of AGS cells treated with LPA, LPA+U0126, LPA+U73122 or LPA+LY294002 (mean \pm standard deviation from three independent experiments; " $\mathrm{P}<0.01$, compared with control group; ${ }^{\text {"P }} \mathrm{P}<0.05$ compared with LPA group). LPA, lysophosphatidic acid; GTP, guanosine triphosphate.

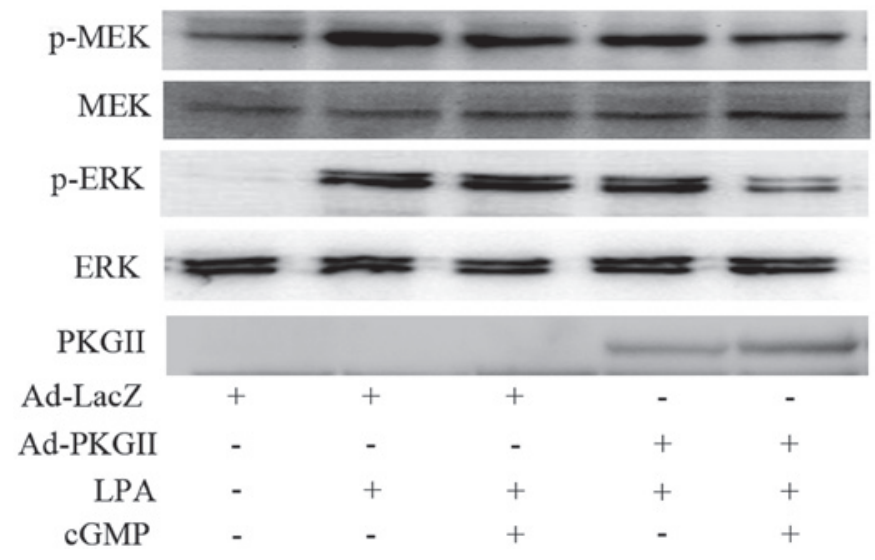

Figure 5. PKG II blocks the phosphorylation of MEK/ERK induced by LPA AGS cells were infected with Ad-LacZ or Ad-PKG II for $48 \mathrm{~h}$ and serum starved overnight. Western blotting was conducted to detect the phosphorylation of MEK and ERK with anti-p-MEK (Ser217/221) and anti-p-ERK (Thr202/Tyr204), respectively. Results shown are representative of three independent experiments. PKG II type II cGMP-dependent protein kinase; LPA, lysophosphatidic acid; cGMP, cyclic guanosine monophosphate; MEK, mitogen-activated protein kinase kinase; ERK, extracellular signal-regulated kinase.

Ad-PKG II, but not in cells infected with Ad-LacZ (Fig. 1C) indicating that PKG II was capable of inhibiting LPA-induced migration of AGS cells.

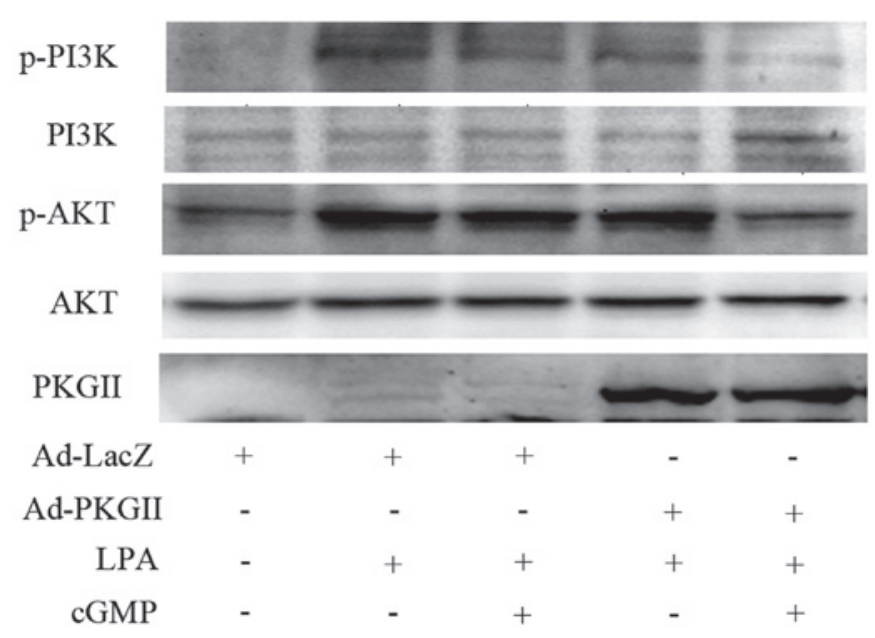

Figure 6. PKG II blocks the phosphorylation of PI3K/Akt induced by LPA AGS cells infected with Ad-LacZ or Ad-PKG II, and treated with LPA or $\mathrm{LPA}+\mathrm{cGMP}$ were subjected to western blotting to detect the phosphorylation of PI3K and Akt, using anti-p-Akt (Ser473) and anti-p-PI3K P85 (Tyr458)/P55 (Tyr199), respectively. Results shown are representative of three independent experiments. PKG II type II cGMP-dependent protein kinase; LPA, lysophosphatidic acid; cGMP, cyclic guanosine monophosphate; Akt, protein kinase B; PI3K, phosphatidylinositol-4,5-bisphosphate 3-kinase.

Pull-down assays confirmed that LPA induced Racl activation, and that the activity of Rac1 was markedly decreased following treatment with 8-pCPT-cGMP in Ad-PKG II infected cells, compared with that of Ad-LacZ infected cells (Fig. 2). The results indicate that inhibition of LPA-induced migration by PKG II is associated with restriction of Racl activity.

Phosphorylation is not associated with PKG II inhibition on Racl activation. To examine the ability of PKG II to directly phosphorylate Rac1 at Ser71, Rac1 was isolated by immunoprecipitation, followed by western blotting with an anti-p-Rac1/Cdc42 (Ser71) antibody. No difference in phosphorylation on the Ser71 residue of Rac1 was observed following 8-pCPT-cGMP treatment in Ad-PKG II infected cells, compared with that of Ad-LacZ infected cells (Fig. 3A). Following this, pan serine/threonine phosphorylation of Rac1 was investigated in the immunoprecipitates. No increase in phosphorylation of serine or threonine residues in Rac1 due to PKG II was observed (Fig. 3B). These data suggest that PKG II-mediated inhibition of Racl activation is not due to direct phosphorylation of Rac1 by PKG II.

PKG II inhibition of Racl activity is associated with activation of MEK/ERK and PI3K/Akt. Cells were pre-treated with LY294002 $(20 \mu \mathrm{M})$, U0126 $(10 \mu \mathrm{M})$ or $\mathrm{U} 73122(10 \mu \mathrm{M})$ to inhibit PI3K, ERK and PLC $\gamma 1$, respectively. Compared with LPA-treated cells in the absence of pre-treatment, LPA-induced Rac1 activity was markedly reduced by LY294002 pre-treatment, and partially reduced by U0126 pre-treatment (Fig. 4); pre-treatment with U73122 had no effect on LPA-induced Rac1 activity. This indicates that MEK/ERK and PI3K may act upstream of Rac1 in the signaling pathway of LPA-induced migration.

The ability of PKG II to inhibit the activation of the MEK/ERK and PI3K was also investigated. Western blotting revealed that PKG II inhibited the LPA-induced phosphorylation/activation of MEK and ERK (Fig. 5) and of PI3K 
and Akt (Fig. 6). These findings support the conclusion that PKG II blocks Rac1 activation by inhibiting MEK/ERK and PI3K/Akt pathways.

\section{Discussion}

PKG II is a subtype of PKG that has been implicated in several physiological functions, including intestinal secretion, bone growth, and nervous system activity (2-4). Increasing evidence indicates that this enzyme may be important in the activity of cancer cells; this may include inhibiting migration and proliferation in certain cancer cell types $(5,7,8)$. Our previous results demonstrated that PKG II may inhibit LPA-induced migration by decreasing RhoA activation (13). The results of the current study suggest that PKG II may inhibit LPA-induced migration of AGS cells by preventing Racl activation. Similar to RhoA, Racl is a member of the small Rho GTPases, which regulate important cellular processes that are associated with cancer cell behavior, such as migration (20). In vivo and in vitro studies over the last decade have firmly established the role of Racl in cancer cell invasion and metastasis. For example, studies have demonstrated that Rac1 may stimulate MMP-1 or MT1-MMP production in lung cancer cell lines and enhance invasion in vitro $(21,22)$. MMP-1 and MT1-MMP are matrix metalloproteinases (MMPs) belonging to a family of extracellular matrix-degrading enzymes and are considered to be important in cancer invasion and metastasis (21). The present study demonstrated that Rac1 activation is essential for LPA-stimulated migration of AGS cancer cells, providing further evidence for the importance of Racl in invasion and metastasis.

PKG signaling is known to inhibit RhoA activity (23). However, whether Racl activation is increased or decreased by PKG II remains to be determined (24-27). In the current study, the results of the pull-down assay revealed that PKG II inhibited LPA-stimulated activation of Rac1, and the direct and indirect effects of PKG II on Racl activation were further investigated to determine the mechanism by which this may occur. Protein kinases may directly regulate the activity of Rho GTPases through phosphorylation, which modulates the GDI affinity and the subcellular localization of the GTPase, thereby negatively affecting its activity (28). RhoA may be phosphorylated by PKA/PKG at Ser-188, and its phosphorylation status is associated with the inhibition of its activity (11). Recently, a similar mechanism was reported for Rac1: Thr108 is phosphorylated by ERK in response to EGF, which alters the interaction of Rac1 with PLC- $\gamma 1$, affecting cell migration (29). Racl may also be phosphorylated by the Akt kinase at Ser71, which results in reduced GTP-binding without affecting GTPase activity (14,30). Previous studies reported a PKG recognition site in Rac1, suggesting that Rac1 may be directly phosphorylated by PKG II (27); however, the results of the present study found no evidence of this interaction.

Potential indirect mechanisms regulating Racl activity were also investigated. PI3K/Akt, MEK/ERK and PLC $\gamma 1$-dependent $\mathrm{Ca}^{2+}$ signaling pathways are major signaling pathways in the regulation of LPA-related migration (31-33). Hu et al (18) demonstrated that EGF stimulates migration of hepatoma cell line HepG2 through GEP100-dependent activation of the Arf6/ERK/Rac1 signaling pathway. Du et al (16) reported that the PI3K and ERK-induced Rac1 activation is required for hypoxia-induced HIF-1 $\alpha$ expression in breast cancer cells. Jones et al (15) proposed that the association of PLC- $\gamma 1$ with complexes containing GIT1 and $\beta$-Pix is essential for its role in integrin-mediated cell spreading and motility, during which the activation of $\mathrm{Cdc} 42$ and Rac1, which are downstream of PLC- $\gamma 1$, is crucial since depletion of $\mathrm{Cdc} 42$ or Rac1 abolishes the elongated cell phenotype. Therefore, the present study explored whether MEK/ERK, PLC- $\gamma 1$ or PI3K/Akt activation is essential in LPA-induced Racl activation. The results revealed that specific chemical inhibitors for PI3K and ERK caused a reduction in LPA-induced Rac1 activity. This indicated that LPA-induced Racl activation may be mediated through PI3K and ERK pathways. The potential inhibitory effect of PKG II on these signal pathways was also investigated, revealing that PKG II prevented LPA-induced activation of PI3K and ERK; this may be the mechanism by which PKG II inhibits gastric cancer cell migration. However, it remains unclear how this inhibition occurs. PKG may directly modify these proteins, or may influence the upstream molecules of these pathways such as $\mathrm{G}$ proteins or the LPA receptor.

In conclusion, the present study has demonstrated that PKG II leads to the inhibition of LPA-induced activation of Rac1 and associated migration in AGS cells. Preliminary investigation of the mechanism indicates that PKG II does not directly inhibit Rac1 through phosphorylation. However, it does inhibit PI3K and ERK mediated signaling, which act upstream of Racl. Further studies are required to elucidate the specific mechanisms.

\section{Acknowledgements}

This study was supported by the National Natural Science Foundation of China (grant nos. 81272755, 31040002 and 81201959) and the Specialized Research Fund for Senior Personnel Program of Jiangsu University (grant no. 11JDG032). The authors would like to thank Dr. Gerry Boss and Dr. Renate Pilz in the University of California (San Diego, CA, USA) for the kind gifts of adenoviral constructs.

\section{References}

1. Ferlay J, Soerjomataram II, Ervik M, Dikshit R, Eser S, Mathers C, Rebelo MM,Parkin DM,Forman D and Bray F: GLOBOCAN 2012 version 1.0, Cancer Incidence and Mortality Worldwide: IARC CancerBase No. 11. International Agency for Research on Cancer [online], 2013. www.globocan.iarc.fr. Accessed January 20, 2014.

2. Pfeifer A, Aszódi A, Seidler U, Ruth P, Hofmann F and Fässler R: Intestinal secretory defects and dwarfism in mice lacking cGMP-dependent protein kinase II. Science 274: 2082-2086, 1996.

3. Miyazawa T, Ogawa Y, Chusho H, Yasoda A, Tamura N, Komatsu Y, Pfeifer A, Hofmann F and Nakao K: Cyclic GMP-dependent protein kinase II plays a critical role in C-type natriuretic peptide-mediated endochondral ossification. Endocrinology 143: 3604-3610, 2002.

4. Tischkau SA, Mitchell JW, Pace LA, Barnes JW, Barnes JA and Gillette MU: Protein kinase G type II is required for night-to-day progression of the mammalian circadian clock. Neuron 43: 539-549, 2004.

5. Swartling FJ, Ferletta M, Kastemar M, Weiss WA and Westermark B: Cyclic GMP-dependent protein kinase II inhibits cell proliferation, Sox 9 expression and Akt phosphorylation in human glioma cell lines. Oncogene 28: 3121-3131, 2009.

6. Fallahian F, Karami-Tehrani F, Salami S and Aghaei M: Cyclic GMP induced apoptosis via protein kinase $\mathrm{G}$ in oestrogen receptor-positive and -negative breast cancer cell lines. FEBS J 278: 3360-3369, 2011. 
7. Chen YC, Ren F, Sang JR, Tao Y and Xu WR: Type II cGMP-dependent protein kinase inhibits proliferation of the gastric cancer cell line BGC-823. Mol Med Rep 3: 361-366, 2010

8. Jiang L, Lan T, Chen Y, Sang J, Li Y, Wu M, Tao Y, Wang Y, Qian $\mathrm{H}$ and $\mathrm{Gu}$ L: PKG II inhibits EGF/EGFR-induced migration of gastric cancer cells. PLoS One 8: e61674, 2013.

9. Etienne-Manneville S and Hall A: Rho GTPases in cell biology. Nature 420: 629-635, 2002.

10. Tapon N and Hall A: Rho, Rac and Cdc42 GTPases regulate the organization of the actin cytoskeleton. Curr Opin Cell Biol 9 : 86-92, 1997.

11. Ellerbroek SM, Wennerberg K and Burridge K: Serine phosphorylation negatively regulates RhoA in vivo. J Biol Chem 278: 19023-19031, 2003.

12. Schwarz J, Proff J, Hävemeier A, Ladwein M, Rottner K, Barlag B, Pich A, Tatge H, Just I and Gerhard R: Serine-71 phosphorylation of Racl modulates downstream signaling. PLoS One 7: e44358, 2012.

13. Wang Y, Chen Y, Li Y, Lan T and Qian H: Type II cGMP-dependent protein kinase inhibits RhoA activation in gastric cancer cells. Mol Med Rep 9:1444-1452, 2014.

14. Schoentaube J, Olling A, Tatge H, Just I and Gerhard R: Serine-71 phosphorylation of $\mathrm{Rac} 1 / \mathrm{Cdc} 42$ diminishes the pathogenic effect of Clostridium difficile toxin A. Cell Microbiol 11:1816-1826, 2009.

15. Jones NP and Katan M: Role of phospholipase Cgamma1 in cell spreading requires association with a beta-Pix/GIT1-containing complex, leading to activation of Cdc42 and Rac1. Mol Cell Biol 27: 5790-5805, 2007.

16. Du J, Xu R, Hu Z, Tian Y, Zhu Y, Gu L and Zhou L: PI3K and ERK-induced Rac1 activation mediates hypoxia-induced HIF-1 $\alpha$ expression in MCF-7 breast cancer cells. PLoS One 6 : e25213, 2011.

17. Ray RM, Vaidya RJ and Johnson LR: MEK/ERK regulates adherens junctions and migration through Rac1. Cell Motil Cytoskeleton 64: 143-156, 2007.

18. Hu Z, Du J, Yang L, Zhu Y, Yang Y, Zheng D, Someya A, Gu L and Lu X: GEP100/Arf6 is required for epidermal growth factor-induced ERK/Racl signaling and cell migration in human hepatoma HepG2 cells. PLoS One 7:e38777, 2012.

19. Schoofs G, Monica TJ, Ayala J, Horwitz J, Montgomery T, Roth $\mathrm{G}$ and Castillo FJ: A high yielding serum-free, suspension cell process to manufacture recombinant adenoviral vectors for gene therapy. Cytotechnology 28: 81-89, 1998.

20. Vega FM and Ridley AJ: Rho GTPases in cancer cell biology. FEBS Lett 582: 2093-2101, 2008.

21. Ridley AJ: Rho proteins and cancer. Breast Cancer Res Treat 84: 13-19, 2004.
22. Soon LL, Yie TA, Shvarts A, Levine AJ, Su F and Tchou-Wong KM: Overexpression of WISP-1 down-regulated motility and invasion of lung cancer cells through inhibition of Rac activation. J Biol Chem 278: 11465-11470, 2003.

23. Langer DA, Das A, Semela D, Kang-Decker N, Hendrickson H, Bronk SF, Katusic ZS, Gores GJ and Shah VH: Nitric oxide promotes caspase-independent hepatic stellate cell apoptosis through the generation of reactive oxygen species. Hepatology 47 1983-1993, 2008

24. Muzaffar S, Shukla N, Bond M, Sala-Newby G, Angelini GD, Newby AC and Jeremy JY: Acute inhibition of superoxide formation and Rac1 activation by nitric oxide and iloprost in human vascular smooth muscle cells in response to the thromboxane A2 analogue, U46619. Prostaglandins Leukot Essent Fatty Acids 78:247-255, 2008.

25. Routray C, Liu C, Yaqoob U, Billadeau DD, Bloch KD, Kaibuchi K, Shah VH and Kang N: Protein kinase G signaling disrupts Rac1-dependent focal adhesion assembly in liver specific pericytes. Am J Physiol Cell Physiol 301:C66-C74, 2011.

26. Rolli-Derkinderen M, Toumaniantz G, Pacaud P and Loirand G: RhoA phosphorylation induces Racl release from guanine dissociation inhibitor alpha and stimulation of vascular smooth muscle cell migration. Mol Cell Biol 30: 4786-4796, 2010.

27. Hou Y, Ye RD and Browning DD: Activation of the small GTPase Rac1 by cGMP-dependent protein kinase. Cell Signal 16:1061-1069, 2004.

28. Forget MA, Desrosiers RR, Gingras D and Béliveau R: Phosphorylation states of $\mathrm{Cdc} 42$ and $\mathrm{RhoA}$ regulate their interactions with Rho GDP dissociation inhibitor and their extraction from biological membranes. Biochem J 361: 243-254, 2002.

29. Tong J, Li L, Ballermann B and Wang Z: Phosphorylation of Rac1 T108 by extracellular signal-regulated kinase in response to epidermal growth factor: a novel mechanism to regulate Rac1 function. Mol Cell Biol 33:4538-4551, 2013.

30. Kwon T, Kwon DY, Chun J, Kim JH and Kang SS: Akt protein kinase inhibits Rac1-GTP binding through phosphorylation at serine 71 of Rac1. J Biol Chem 275: 423-428, 2000.

31. Bian D, Su S, Mahanivong C, Cheng RK, Han Q, Pan ZK, Sun P and Huang S: Lysophosphatidic Acid Stimulates Ovarian Cancer Cell Migration via a Ras-MEK Kinase 1 Pathway. Cancer Res 64: 4209-4217, 2004

32. Kim EK, Yun SJ, Do KH, Kim MS, Cho M, Suh DS, Kim CD, Kim JH, Birnbaum MJ and Bae SS: Lysophosphatidic acid induces cell migration through the selective activation of Akt1. Exp Mol Med 40: 445-452, 2008.

33. Jans R, Mottram L, Johnson DL, Brown AM, Sikkink S, Ross K and Reynolds NJ: Lysophosphatidic acid promotes cell migration through STIM1- and Orai1-mediated Ca2+(i) mobilization and NFAT2 activation. J Invest Dermatol 133: 793-802, 2013. 